\title{
Humanistic Information Science
}

Feinberg, Melanie; Furner, Jonathan; Mai, Jens-Erik; Tennis, Joseph

Publication date:

2012

Document version

Early version, also known as pre-print

Citation for published version (APA):

Feinberg, M., Furner, J., Mai, J-E., \& Tennis, J. (2012). Humanistic Information Science. Abstract from ASIST Annual Meeting, Baltimore, United States. http://www.asis.org/asist2012/abstracts/151.html 


\section{Humanistic Information Science}

\author{
Melanie Feinberg \\ School of Information \\ University of Texas at Austin \\ Austin, Texas, USA \\ feinberg@ischool.utexas.edu \\ www.ischool.utexas.edu/ feinberg \\ Jens-Erik Mai \\ Royal School of Library and \\ Information Science \\ Copenhagen, Denmark \\ jem@iva.dk \\ jenserikmai.info
}

\author{
Jonathan Furner \\ Dept. of Information Studies \\ University of California, Los Angeles \\ Los Angeles, CA, USA \\ furner@gseis.ucla.edu \\ furner.info
}

\author{
Joseph Tennis \\ Information School \\ University of Washington \\ Seattle, WA, USA \\ jtennis@uw.edu \\ faculty.washington.edu/jtennis
}

\begin{abstract}
The panel presents approaches to information science that are grounded in humanities, and argues that the field could be richer if it embraces humanistic approaches to information science. While the field has broadened and changed significantly since ASIST was founded 75 years ago, it is suggested that information science continues to be committed to objectivistic understandings of what is most properly involved in social scientific inquiry. The panelists will present understandings of information science as the field concerned with the fundamental relation between people and reality, and with the culturally-specific roles that information plays in the practices that constitute this relation. The panelists will present a range of scholarly research topics in humanistic information science that will be used as the springboard for interactions with the audience about the future of a humanistic information science.
\end{abstract}

\section{Keywords}

Information science, humanities, foundation, history.

\section{INTRODUCTION}

As ASIST celebrates its $75^{\text {th }}$ anniversary, it is appropriate to explore what information science has been, what it is, and what it could be. This panel will advocate the expansion of

ASIST 2012, October 28-31, 2012, Baltimore, MD, USA.

(C) Melanie Feinberg, Jonathan Furner, Jens-Erik Mai \& Joseph Tennis. information science to embrace humanistic approaches to information science.

For much of the past 75-year period, conceptualizations of information science have commonly been based on objectivistic understandings of what is most properly involved in social scientific inquiry. It has frequently been assumed, for example, that a primary goal of information science is to uncover the "true" nature of information; that that goal can be met by studying people's interactions with information; and that it is plausible for the result of such inquiry to be that information is something that flows between people and material objects. This kind of conceptualization was popularized with Harold Borko's famous definition of information science from 1968:

"Information science is a discipline that investigates the properties and behavior of information, the forces governing the flow of information, and the means of processing information for optimum accessibility and usability. It is concerned with that body of knowledge relating to the origination, collection, organization, storage, retrieval, interpretation, transmission, transformation, and utilization of information. This includes the investigation of information representations in both natural and artificial systems, the use of codes for efficient message transmission, and the study of information processing devices and techniques such as computers and their programming systems. It is an interdisciplinary science derived from and related to such fields as mathematics, logic, linguistics, psychology, computer technology, operations research, the graphic arts, communications, library science, management, and other similar fields. It has both a pure science component, which inquires into the subject without regard to its application, and an applied science 
component, which develops services and products." (Borko, 1968)

Borko's definition and conceptualization of information science as the field that focuses on establishing the properties of information as a material entity was an attempt to rhetorically group information science along with other sciences that study natural phenomena. Since the 1960s, of course, many others have successfully advocated for the strengthening of interdisciplinary ties between information science and various of the social sciences, as well as for the application of a wide range of qualitative methods in information science research.

This panel will present the case that even this more-broadly conceived approach to the study of information is a limited and limiting conceptualization of the object and field of study. Panel members will propose a number of humanistic approaches to information which, taken together, amount to a view of information science as the field concerned with nothing less than the fundamental relation between people and reality.

On this view, a primary goal of information science is to understand the culturally-specific roles that conceptions of information play in the fundamental everyday-life practices of representation, interpretation, meaning-making, classification, storytelling, remembering, forgetting, etc. Fields of study that are closely aligned with this view include rhetoric, cultural studies, genre theory, narratology, philosophy of language, semiotics, and media theory.

\section{THE PANEL}

The panel will provide opportunity for the audience to engage in discussions about the future of information science, and especially about paths towards to a solid foundation for a humanistic information science. The panelists will provide grounding for the discussions and outline challenges that need addressing.

The moderator will briefly introduce the topic and each panelist will give a short (approx. 10-minute) presentation in which they outline their take on innovative and groundbreaking research agendas. Each panelist will address foundational questions to be explored within a humanistic information science:

- What makes any field of inquiry a "humanistic" one?

- What would a humanistic information science be like?

- Why should information science strive to be humanistic?

Specific topics to be discussed by individual panelists will include:

- As one of the defining concepts of the field, information continues to be discussed and redefined as the field matures and evolves. It is suggested that an understanding of information as sign will provide a proper, broad and inclusive understanding of information and information science as a field concerned with people and their understanding of reality.

- The relationship between information studies, cultural studies, genre studies, media studies, and digital humanities.

- Time and intentionality in indexing requiring an interpretive stance. This is humanistic in that there is no nomothetic arch to arguing for intentionality in indexing. Time as a cultural construct, if it is to be incorporated into information systems, requires a rhetorical stance. This is a position of argument and by nature is a humanistic method.

- Humanistic approaches to information as necessary for visionary professional practice. If information systems operate on a cultural plane, as we contend, then the professionals who design, maintain, and provide instruction for using these systems must incorporate active understanding of their cultural mechanisms into their work activities.

After the panelists have given their presentations, the audience members will engage with the panel and with one another in discussions about the topic. The moderator will facilitate the discussion and the key questions proposed by the panelists will be used as the springboard for the discussion.

The aim of the discussion, and of the panel in general, is to bring about an awareness of the challenging issues that lie ahead in advancing a humanistic information science, and ultimately to move information science towards a broader and more inclusive conception of its nature, scope, and methodology.

\section{PANELISTS}

Melanie Feinberg: Assistant professor, School of Information, University of Texas. Feinberg's research considers collections as a form of creative expression. She investigates how collections suggest particular meanings for their contents and focuses on three related areas, theory, design, and criticism.

Jonathan Furner: Associate professor, Department of Information Studies, University of California, Los Angeles. Furner works on projects in cultural informatics and in the history and philosophy of information science. He is especially interested in the modes in which cultural institutions (i.e., libraries, archives, museums, etc.) create, organize, and record descriptions of the resources (i.e., books, artworks, images, etc.) that they collect.

Jens-Erik Mai: Professor, Royal School of Library and Information Science. Mai asks basic questions about the nature of information phenomena; he has explored these from a variety of conceptual points (e.g. semiotics, 
cognitive work analysis, late-modernity, philosophy of language, trust) often with a focus on issues and questions in the organization of information.

Joseph Tennis: Assistant professor, Information School, University of Washington. Tennis' work grows out of the assumptions that we have methodologies for designing classification schemes, but we do not have a firm understanding of evaluating the management of large installed semantic systems over time and in a networked environment.

\section{REFERENCES}

Borko, H. (1968). "Information science: what is it?" American Documentation 19(1): 3-5. 